\title{
La judicatura en el sistema constitucional ruso
}

Judiciary on Russian Constitutional System

\author{
VLADISLAV ARKHIPOV*, DMITRIY BARTENEV**, \\ SERGEY BELOV ${ }^{* * *}$, OLGA KUDRYASHOVA***, \\ DIANA MUSHTAKOVA****, ILYA VASIL'EV
}

\begin{abstract}
Resumen: El presente artículo se detiene a analizar el papel de la judicatura en el sistema constitucional ruso a partir de la Constitución de 1993, aquella que sustituyó a la Constitución de 1978 de la República Socialista Federativa de la Unión Soviética que estaba basada en la ideología comunista. Así, con la finalidad de dar cuenta del nuevo orden constitucional, enfatiza en importantes aristas como el principio de separación de poderes, los derechos humanos y libertades reconocidos constitucionalmente, la interrelación entre la jurisprudencia de los órganos internacionales de derechos humanos y la Corte Constitucional de Rusia, entre otros.
\end{abstract}

Palabras clave: sistema constitucional - Rusia - separación de poderes judicatura - derechos humanos - libertades - jurisprudencia

Abstract: This article is about new constitutional order in Russia emphasizing fundamental areas as the role of judiciary in the Russian Constitutional System from 1993 Constitution, the one which replaced the 1978 Russian Soviet Federative Socialist Republic Constitution based on communist ideology. Therefore, it is intended to examine the principle of separation of powers, constitutionally recognized human rights and liberties, relationship between international bodies' case law of human rights and the Russian Constitutional Court, among others issues.

Key words: constitutional system - Russia - separation of powers - judiciary human rights - liberties - case law

CONTENIDO: I. BREVE PRESENTACIÓN DE LA HISTORIA CONSTITUCIONAL RUSA.- II. CONTROL Y BALANCE EN EL SISTEMA CONSTITUCIONAL RUSO.- III. DERECHOS HUMANOS Y LIBERTADES RECONOCIDOS EN LA CONSTITUCIÓN RUSA.- III.1. DERECHOS PERSONALES.- III.2. DERECHOS POLÍTICOS.- III.3. DERECHOS SOCIALES, ECONÓMICOS Y CULTURALES.III.4. LOS LÍMITES DE LOS DERECHOS HUMANOS.- IV. TRIBUNAL CONSTITUCIONAL Y REVISIÓN JUDICIAL.- IV.1. PANORAMA GENERAL.IV.2. OPORTUNIDADES Y DESAFÍOS.- IV.3. EL EXCESO DE PODERES.-

\footnotetext{
PhD, profesor asociado de la Universidad Estatal de San Petersburgo (Rusia).

PhD, profesor asistente de la Universidad Estatal de San Petersburgo (Rusia).

** PhD, profesor asociado de la Universidad Estatal de San Petersburgo (Rusia).

...* Profesor asistente de la Universidad Estatal de San Petersburgo (Rusia).

..... Profesor asistente de la Universidad Estatal de San Petersburgo (Rusia).

...... PhD, profesor asistente de la Universidad Estatal de San Petersburgo (Rusia).
} 
IV.4. FUNCIÓN LEGISLATIVA DE FACTO DE LA CORTE.- V. EL DERECHO INTERNACIONAL DE DERECHOS HUMANOS Y LA JURISPRUDENCIA DE LA CORTE CONSTITUCIONAL DE LA FEDERACIÓN RUSA.

\section{BREVEPRESENTACIÓNDELAHISTORIACONSTITUCIONAL RUSA}

La Constitución rusa de 1993 incorpora el nuevo escenario del desarrollo del Estado de Rusia y los sistemas legales. Previamente, la Constitución de 1978 de la República Socialista Federativa de la Unión Soviética (RSFSR) era la Ley Fundamental, la cual estaba basada en la ideología comunista.

El propósito de adoptar la nueva Constitución de 1993 era definir el nuevo marco legal de las relaciones entre los individuos y el Estado. La Constitución se convirtió en uno de los símbolos de los cambios sociales radicales en la sociedad rusa y estableció un nuevo orden constitucional, similar al de Europa Occidental y al tipo de democracia de Estados Unidos. Para ello, la Constitución no solo rechazó las instituciones constitucionales de la RSFSR de 1978, sino también sus principios fundamentales.

Al mismo tiempo, el trasplante de los nuevos principios jurídicos haría considerar que la cultura y las tradiciones jurídicas de la sociedad rusa no eran un tabula rasa. El sistema constitucional ruso se convirtió en una mixtura de los principios de la democracia constitucional y las tradiciones jurídicas del sistema legal soviético y de su ideología.

El principio de la soberanía del pueblo fue reconocido a partir de la Constitución de 1993, identificando a las personas multinacionales de la Federación Rusa como titulares de la soberanía y como única fuente de poder. No tardó mucho para que el Estado fuera visto como una entidad colectiva que cubría a la totalidad de la sociedad, como una especie de organización de trabajadores, de modo que ponía en el mismo nivel a la sociedad y a sus miembros. El Estado ruso, dentro del significado de las disposiciones de la Constitución, tiene la condición de documento representativo de la sociedad. Sobre esa base, la Constitución vigente reconoce la igual importancia de los derechos personales, políticos, sociales y económicos y de las libertades. Este importante rasgo distingue a la Constitución de 1993 de su antecesora.

El sistema constitucional soviético no reconoció el principio de separación de poderes, favoreciendo así al principio de la democracia centralizada y proporcionando en esta medida el poder estatal, para políticamente consolidar la clase social hegemónica. Con el tiempo, la dictadura del Estado soviético retrocedió. 
Con la adopción de la Constitución de 1993, la necesidad política de la separación de poderes adquirió obligatoriedad legal. La separación de poderes, como un sistema de control y balance del poder, fue la forma de establecer el régimen democrático y alcanzar el buen gobierno. La interpretación de este principio envolvió la coordinación de las autoridades de todos los Estados desde un centro político.

El presidente de la Federación Rusa no era miembro de ninguna rama del gobierno y llevó a cabo la coordinación como garante de la Constitución. En la judicatura, la separación de poderes prohibió la concesión de cualquier facultad normativa a las cortes. Esta prerrogativa fue reservada a la legislatura.

La Constitución de 1993 definió la nueva estructura de la judicatura, estableciendo, entre otros principios, el del control de constitucionalidad. Tomadas del Estado soviético, fueron organizadas tres subramas de la judicatura: en un primer momento, las cortes de jurisdicción ordinaria (principalmente enfocadas en temas civiles, administrativos y penales) y las cortes estatales de arbitraje comercial (las cuales resolvían en su mayoría disputas civiles y administrativas, donde participaban diversos empresarios). La tercera subrama apareció como la nueva institución del control de constitucionalidad y recibió la denominación de Corte Constitucional Federal. Las cortes de arbitraje, que en la mayoría de judicaturas extranjeras son las organizaciones no estatales, en la Constitución de 1993 fueron conservadas como cortes estatales de la tradición soviética.

El constitucionalismo soviético no admitió la protección de los derechos de los ciudadanos sino solo en el ámbito nacional; es decir, no reconoció ninguna jurisdicción internacional en esta materia. La Constitución de 1993, a diferencia de la Constitución previa, estableció la prioridad de los tratados internacionales sobre la legislación nacional —e incluso sobre la Constitución en sí misma - y el derecho de las personas de denunciar las violaciones a sus derechos ante los tribunales internacionales. Luego, en 1998, el Parlamento ruso ratificó el Convenio Europeo para la Protección de los Derechos Humanos y de las Libertades Fundamentales, reconociendo ipso facto la jurisdicción del Tribunal Europeo de Derechos Humanos.

Bajo la concepción constitucional soviética, basada en la ideología marxista materialista, se dio prioridad a los derechos sociales y económicos — como los derechos a trabajar, al descanso y tiempo libre o a la seguridad social- sobre los derechos civiles o políticos. En el discurso político soviético se declaró que no eran necesarios los derechos políticos si las condiciones sociales y económicas no eran proporcionadas. La Constitución de 1993 declaró un número de esos derechos sociales, incluyendo los derechos de protección 
a la salud y asistencia médica gratuita en las ambulancias del Estado, el derecho a la vivienda (las viviendas para los más necesitados eran provistas por el Estado), el derecho a la educación, etc. Dentro de la economía liberal de mercado, estos derechos no se llevaban a cabo en la práctica, así que llegaron a ser normas jurídicas tradicionales, pero meramente ostentosas.

El principio «burgués» del imperio de la ley fue rechazado en el constitucionalismo soviético por ser considerado vago y por dar un amplio margen de discrecionalidad a las cortes. En reemplazo, la Constitución soviética reconoció el principio de «legalidad socialista», visto como la interpretación literal y ejecución correspondiente de las leyes y reglamentos de los órganos de gobierno del Estado soviético, los funcionarios, los ciudadanos y las organizaciones de la sociedad civil. La Constitución de 1993 mencionó a ambos —al principio de legalidad y al principio de imperio de la ley-, dando amplio espacio de elección para la aplicación de cualquiera de estos. En la práctica, el principio del imperio de la ley abrió camino a la implementación directa de la Constitución. La Corte Constitucional Rusa apela al principio del imperio de la ley, exige certeza a las normas legales, y definición de las consecuencias de las acciones legales para las personas, etc.

La concepción soviética del principio de bienestar («social», en la Unión Soviética «socialista») fue también distinta de la existente en la democracia liberal. El principio de socialismo construyó un Estado paternalista con dominio de la propiedad estatal, con un tipo de planificación administrativa y con un estado de financiación de todos los gastos de atención social. La Constitución de 1993 cambió este principio por el liberal Sozialstaat, pero la discusión acerca de la correcta comprensión de este principio sigue formando parte de la agenda de Rusia. La presencia del Estado en la economía en Rusia aún es dominante, y las expectativas de las personas de obtener apoyo del Estado aún son exageradas. El principio del Estado social a menudo es entendido como el derecho a que se distribuya la renta nacional entre la población. Todos estos ejemplos demuestran el cambio radical del Estado y del sistema legal con la Constitución de 1993; sin embargo, la comprensión de muchos de estos principios aún es distinta de aquella en el extranjero, aunque el conjunto de estos principios es en cambio muy parecido a muchas de las democracias extranjeras. Las características generales del nuevo sistema constitucional de Rusia serán desarrolladas a continuación. 


\section{CONTROL Y BALANCE EN EL SISTEMA CONSTITUCIONAL RUSO}

La Constitución de la Federación Rusa establece la separación de poderes como el principio eje del sistema de gobierno ${ }^{1}$. Según este principio constitucional, el poder del Estado, siendo un todo singular, al mismo tiempo está dividido en tres poderes: legislativo, ejecutivo y judicial. Cada uno es independiente y sus autoridades actúan en determinadas formas jurídicas y a través de organismos gubernamentales específicos. Ello no significa que los poderes del Estado estén absolutamente aislados uno del otro; por el contrario, estos interactúan según el sistema de control y balance. Este sirve como garantía ante la brecha entre los poderes y ante la concentración del poder en uno solo.

El Poder Judicial, en igualdad con otras ramas de poder, está establecido en la Constitución rusa (artículo 11) como independiente y autónomo. $\mathrm{Su}$ característica distintiva es la específica función que cumple: la administración de la justicia. Los tribunales son especializados y las únicas autoridades del Estado que deciden las controversias jurídicas entre los miembros de la sociedad, así como las disputas entre estos y las instituciones gubernamentales de la administración de justicia. Según la Constitución de la Federación Rusa (artículo 18), la administración de justicia es una función exclusiva de los tribunales, llevada a cabo en determinadas formas jurídicas, mientras que otras instituciones no están autorizadas para ello. Siendo una forma especial de actividad del poder, el Poder Judicial se distingue por sus objetivos, contenido y procedimiento. Asimismo, y conforme al artículo 18 de la Constitución rusa, la administración del poder se divide en diferentes procedimientos judiciales: constitucional, civil, administrativo y penal.

En su capítulo 7, referido al Poder Judicial, la Constitución rusa establece las bases institucionales para aquel y menciona a los más altos tribunales: la Corte Constitucional (artículo 25), la Corte Suprema (artículo 126) y el Tribunal Supremo de Arbitraje (artículo 127). Entretanto, la Constitución no describe a la totalidad del sistema judicial y tampoco enumera la lista exhaustiva de tribunales. El sistema judicial se concreta en la ley especial de la Constitución Federal «En el sistema judicial». De conformidad con esta ley, el sistema judicial integrado se compone de tres tipos de tribunales entre los cuales se divide la función judicial: tribunales constitucionales, tribunales de jurisdicción ordinaria y tribunales de arbitraje (artículo 4). Los tribunales de jurisdicción ordinaria, así como los tribunales de arbitraje, son sistemas de organización jerárquica en los cuales la competencia está dividida horizontalmente (jurisdicción territorial) y verticalmente (jurisdicción sujeta a la complejidad del caso). Este sistema jerárquico tiene como objetivo que los tribunales 
superiores comprueben las decisiones de los tribunales inferiores. Además, la ley divide al Poder Judicial entre los tribunales federales y los tribunales encargados de las materias de la Federación, los cuales son la Corte Constitucional de la Federación y el magistrado (artículo 4).

Según la Constitución rusa (artículo 120), el Poder Judicial se caracteriza por su independencia y solo puede someterse a la Constitución y a la ley. Pero no se encuentra aislado de las otras ramas del poder, por el contrario, está sometido al sistema de control y balance. Sobre todo, interactúa de sobremanera con el Poder Legislativo. Por un lado, el Poder Legislativo ejerce influencia sobre el Poder Judicial. En primer lugar, establece las bases legales de la organización de los tribunales, la condición jurídica de los jueces y los procedimientos judiciales. En segundo lugar, los jueces, al decidir los casos, deben guiarse por las leyes emitidas por el Poder Legislativo. En tercer lugar, el Poder Legislativo participa en el nombramiento de los jueces supremos: el Consejo de la Federación nombra a los jueces del Tribunal Constitucional, de la Corte Suprema y del Tribunal Supremo de Arbitraje (artículo 128).

Por otro lado, el Poder Judicial influye sobre el Poder Legislativo. En primer lugar, la Corte Constitucional, la Corte Suprema y el Tribunal Supremo de Arbitraje tienen el derecho de iniciativa legislativa en materias de su competencia (artículo 104). En segundo lugar, las Cortes Constitucionales (la Corte Constitucional de la Federación Rusa y los tribunales encargados de las materias de la Federación) están facultadas para demandar acciones de inconstitucionalidad que, de ser el caso, supondrán la pérdida de eficacia jurídica de la norma. En tercer lugar, los tribunales que administran justicia, dentro de su competencia, dan recomendaciones para el mejoramiento de la legislación, las cuales, si bien no son obligatorias, pueden servir como líneas directrices para el legislador.

El Poder Judicial, además, interactúa enormemente con el Poder Ejecutivo y con el presidente de la Federación Rusa. El gobierno prepara el presupuesto que abarca a todas las autoridades estatales, incluyendo a los tribunales (artículo 114 de la Constitución rusa). El presidente propone a los candidatos para el Consejo de la Federación, para el nombramiento de los jueces de los tribunales superiores, y nombra a los jueces del resto de tribunales federales (artículo 83 de la Constitución de Rusia). En segundo lugar, los jueces que deciden los casos no deben solo guiarse por las leyes, sino también por los actos normativos del presidente y de los organismos del Poder Ejecutivo.

Por otra parte, el Poder Judicial tiene la facultad de privar de efectos legales a los actos y decisiones del presidente y de los organismos del Poder Ejecutivo en los procedimientos administrativos (siempre que esos actos o decisiones violen la ley) y en los procedimientos constitucionales 
(si los actos normativos son contrarios a la Constitución). La Corte Constitucional y la Corte Suprema participan en el procedimiento de destitución del presidente (artículo 93).

La participación del Poder Judicial en el sistema de control y balance se hace también evidente en la actividad judicial considerada subsidiaria a la justicia y caracterizada en cierta medida como ejecutiva o como de elaboración de normas. Los poderes ejecutivos están condicionados por el sistema jerárquico de los tribunales de jurisdicción ordinaria y por los tribunales de arbitraje, en virtud de los cuales los tribunales superiores tienen la facultad de revisar las decisiones de los tribunales inferiores.

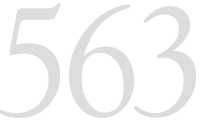

LA JUDICATURA EN EL SISTEMA CONSTITUCIONAL RUSO

JUDICIARY ON

RUSSIAN CONSTITUTIONAL SYSTEM

La cuestión más discutible es la posibilidad de elaboración de normas por parte del Poder Judicial. En la ciencia jurídica y en la práctica jurídica, hay defensores y opositores de esta posibilidad. La perspectiva de los oponentes está basada en la doctrina soviética, la cual no reconoció al precedente judicial como fuente legal, y en la tradición legal rusa, que históricamente separó la elaboración de normas de las funciones judiciales. Según esta visión, la posibilidad de elaborar normas contraviene la naturaleza de los tribunales y puede ser incluso considerada una invasión en la competencia del parlamento. Los partidarios, en cambio, opinan que la posibilidad de elaboración judicial de las normas coexiste con el poder de legislar del Parlamento, y que se distinguen uno del otro. Las características específicas de la elaboración judicial de las normas son las siguientes: en primer lugar, esta es administrada por una institución específica, el tribunal; en segundo lugar, es administrada en un procedimiento específico; en tercer lugar, no está supeditada a las necesidades de las regulaciones legales, sino a las contradicciones en las regulaciones legales; en cuarto lugar, está limitada por el objeto de la solicitud ${ }^{2}$.

El reconocimiento de la elaboración judicial de las normas usualmente se atribuye a los tribunales superiores: principalmente a la Corte Constitucional, y en cierta medida, a la Corte Suprema y al Tribunal Supremo de Arbitraje. Las sentencias de los tribunales superiores suelen dividirse en dos tipos: las sentencias de aplicación de las leyes y las sentencias de elaboración de las normas. Estas últimas tienen características normativas: contienen regulaciones generales destinadas a aplicaciones múltiples y para el público general. Tenemos ejemplos de tales juicios en la Corte Suprema y en el Tribunal Supremo de Arbitraje, en los cuales se interpreta la norma y se explica cómo los tribunales inferiores deben aplicar las disposiciones jurídicas inciertas³.

2 Ver MARCHENKO, M. "Sudebnoe pravotvorchestvo i sudebnoe pravo» (Judicial rule-making and judicial law). Perspectiva, 2011 (en ruso).

3 Ver sentencia del Pleno de la Corte Suprema del 31.10.1995, № 8. 
Las principales discusiones giran en torno a la facultad de elaboración de normas por la Corte Constitucional rusa. En la doctrina jurídica, hay posiciones disparejas acerca de la posición de la Corte Constitucional en el sistema de poderes. Por un lado, y basados directamente en las provisiones constitucionales (capítulo 7), la Corte Constitucional es solo parte del íntegro del Poder Judicial y constituye uno de los más altos tribunales. Se encarga de administrar una determinada forma de justicia: la justicia constitucional. Por otro lado, la Corte Constitucional es un cuasi tribunal cuyas características específicas lo distinguen de los tribunales ordinarios (por ejemplo, la ausencia de controversia sobre derechos en algunos casos, la forma de llevar a cabo el principio de contradicción y la ignorancia en la averiguación de hechos).

Algunos constitucionalistas consideran que la Corte Constitucional, debido a sus características específicas, es más que un simple tribunal y está por encima de la separación de poderes ${ }^{4}$. Esta perspectiva se enfoca en las funciones específicas de la Corte. En primer lugar, la Corte resuelve los conflictos de competencia entre las autoridades del Estado Federal, entre las autoridades relacionadas con los temas de la federación, y entre ambos. En segundo lugar, la Corte decide las cuestiones de constitucionalidad de los actos normativos. En tercer lugar, la Corte interpreta la Constitución.

Aunque la Constitución y la legislación no proporcionan ninguna competencia a la Corte Constitucional para elaborar normas, el análisis de esta práctica hace a la mayoría de constitucionalistas rusos reconocer el rol significativo de la Corte Constitucional en la elaboración de normas ${ }^{5}$.

La declaración de inconstitucionalidad de las normas en sí misma a menudo es caracterizada como una forma de legislación negativa. Esta incluye la privación de efectos jurídicos de las normas, pero no necesariamente la creación de nuevas normas.

Una de las formas de influencia normativa de la Corte Constitucional en el proceso de elaboración de normas está en las recomendaciones al legislador que la Corte formula como resultado de escuchar el caso. Estas recomendaciones no son obligatorias, pero suelen servir como parámetro para mejorar el derecho según los requerimientos constitucionales. Por ejemplo, en el juicio del 5.02.2007, la Corte recomendó al legislador reformar la instancia de supervisión judicial de acuerdo con los requisitos constitucionales y las obligaciones

4 Ver BONDAR, N. Sudebnyi konstitutionalizm v Rossii (Constitucionalismo judicial en Rusia). Moscú: Norma, 2011 (en ruso).

5 Ver GRICENKo, E. "Predely konstitutionno-sudebnogo normotvorchestva" (Límites de la reglamentación constitucional judicial). Sravnitel'noe konstitutionnoe obozrenie, 2011, № 5. (en ruso). 
internacionales ${ }^{6}$. Entretanto, la práctica ha demostrado que el legislador no sigue inmediatamente las recomendaciones de la Corte.

Además de la conclusión sobre la constitucionalidad de las provisiones legales y las recomendaciones al legislador, las decisiones de la Corte Constitucional pueden contener posiciones legales generales reconocidas como normas?

La Corte Constitucional por sí misma afirma el carácter normativo de sus decisiones, lo que lo distingue de las decisiones de otros tribunales ${ }^{8}$. En el juicio del 16.06.1998, la Corte indicó que sus decisiones tienen las mismas características y efectos legales que los actos normativos, aspecto que no comparten las sentencias emitidas por otros tribunales. En la resolución del 8.10.1998, la Corte difundió las características normativas de las posiciones legales en las que interpreta la disposición constitucional y revela el sentido constitucional del acto legal ${ }^{9}$.

En la mayoría de casos, la actividad de elaboración de las normas es realizada por la Corte a través del uso del método de interpretación constitucional de los actos legales, lo cual es típico para los modelos continentales de justicia constitucional. La actividad de interpretación de la Corte es útil no solo para la clarificación del sentido de las disposiciones legales, sino también para llenar los vacíos legales con nuevo contenido y para corregir la aplicación de la ley basada en dicha disposición legal.

Con la interpretación constitucional, la Corte en algunos casos especifica el sentido de las normas constitucionales. Por ejemplo, en el juicio del $12.04 .1995^{10}$, interpretó la noción constitucional de «número total de miembros del Estado de Duma» y el «número total de miembros del Consejo de la Federación» en el procedimiento legislativo. La Constitución no determina si la noción de «número total» significa el número mencionado en la Constitución, o el número de miembros elegidos en la práctica. La Corte Constitucional decidió que esta noción debe ser entendida como el número de miembros según lo dispuesto por la Constitución. Esta interpretación estuvo basada en el argumento de que la mayoría de los que constituyen el Estado de Duma no pueden ser reconocidos como representantes del pueblo, y por lo tanto, no tienen poder para adoptar actos legítimos. El otro ejemplo es el juicio del 25.3.1995, en el cual la Corte decidió la cuestión de si la disposición constitucional contenida en el artículo 105 (inciso 4), según el cual el acto es aprobado si el Consejo

6 Juicio de la Corte Constitucional del 5.01.2007 № 2-P.

7 Ver BONDAR, N. Judicial constitutionalism in Russia. Moscú: Norma, 2011 (en ruso).

8 Juicio de la Corte Constitucional del 16.06.1998 № 19-P.

9 Resolución del Tribunal Constitucional del 8.10.1998 № 118-O.

10 Juicio de la Corte Constitucional del 12.04.1995 № 2-P.

LA JUDICATURA

EN EL SISTEMA CONSTITUCIONAL RUSO

JUDICIARY ON

RUSSIAN CONSTITUTIONAL SYSTEM 
de la Federación no lo aprueba o rechaza en catorce días, puede ser aplicada a los actos que, según el artículo 106 de la Constitución, deben ser de manera obligatoria considerados por el Consejo de la Federación. La Corte decidió que el Consejo de la Federación debe empezar por examinar este tipo de actos en un plazo no mayor de catorce días, pero hasta que no termine la consideración, no puede reconocerse que el acto ha sido aprobado ${ }^{11}$. De hecho, esta es una nueva norma que la Constitución no contenía.

Aunque la Corte Constitucional no tiene normativamente el poder de interpretar las leyes ni otros actos normativos, un número significativo de sus casos, en vez de reconocer la inconstitucionalidad de las disposiciones legales, evalúa la constitucionalidad de su entendimiento en la práctica y concretiza complementos e incluso cambios al contenido de las disposiciones legales hechas por sí misma, en vez del legislador ${ }^{12}$. Por ejemplo, en la resolución del 8.02.2001, la Corte llenó de un nuevo sentido a una provisión del Código Laboral (anterior a la emisión de la Constitución), la cual no permitía la disolución de un contrato laboral por el empleador en caso de robo de la propiedad privada ${ }^{13}$. Otro ejemplo es el juicio del 11.06.2003, en el cual la Corte reclamó que el sentido constitucional del acto «en referéndum» supone que el período durante el cual el referéndum puede ser iniciado no debe ser inferior a dos años ${ }^{14}$.

Así, la Corte corrige la legislación y la aplicación de la ley. Pero en cuanto a la función de interpretación de la ley, esta no está normativamente establecida como la actividad de la Corte, y es criticada en la doctrina legal como una invasión al Poder Legislativo, así como a la competencia de otras altas cortes ${ }^{15}$. La función de interpretación de la ley realizada por la Corte Constitucional se ha convertido en el conflicto de competencias de la Corte Constitucional y otras cortes que usualmente llevan a cabo la función de interpretación de la ley. Por otra parte, en algunas resoluciones la Corte se determina los errores en las decisiones tomadas por otras cortes y se recomienda al solicitante recurrir ${ }^{16}$. Muchos constitucionalistas rusos indicaron que la Corte, al interpretar actos legales y evaluar la aplicación de la ley de conformidad con dichos actos, invade la competencia de otras cortes y su derecho a aplicar la Constitución de manera directa ${ }^{17}$.

\footnotetext{
11 Juicio de la Corte Constitucional del 23.03.1995 № 1-P.

12 Ver GRICENKO, E. Ob. cit.

13 Ver GRICENKo, E. Ob. cit.

14 Juicio de la Corte Constitucional del 11.06.2003 № 10-P.

15 Ver BeLov, S., O. Beglova Zaimstvovanie kontinental'noy modeli konstitucionnogo kontrolya $v$ rossiyskoy pravovoy systeme Borrowing of the continental model of constitutional control in Russian legal system (Zhurnal konstitucionnogo pravosudiya, 2012, № 6) (en ruso).

16 Resolución del 8.12.2011 № 1624-O-O.

17 Ver Belov, S., O. Beglova. Ob. cit.
} 


\section{III.DERECHOS HUMANOS Y LIBERTADES RECONOCIDOS EN LA CONSTITUCIÓN RUSA}

La Constitución rusa de 1993 reconoce y garantiza los derechos humanos y libertades de conformidad con los principios universalmente aceptados y las normas del derecho internacional y de conformidad con la Constitución (ítem 1, artículo 17).

Esta declaración desarrolla la disposición establecida en el artículo segundo de la Constitución, que declara lo siguiente: «El ser humano, sus derechos y libertades deben ser el valor supremo. El reconocimiento, el respeto y la protección de los derechos y libertades del ser humano y del ciudadano son deberes del Estado». Debe observarse que las dos disposiciones mencionadas se refieren a los capítulos que no pueden ser revisados por el Poder Legislativo y que requieren el llamado del Convento Constitucional.

El texto de la Constitución, así como la teoría de los derechos humanos, aunque con una mínima diferencia, hacen una diferenciación entre «derechos»y «libertades». Sin embargo, tal diferencia tiene mayor importancia semántica que legal. A menudo se hace hincapié en que el término «libertad» es más amplio, mientras que el término «derecho» usualmente se refiere a algo definido de manera menos precisa. Por ejemplo, la Constitución provee la libertad de pensamiento y expresión (ítem 1, artículo 29) y el derecho a reunirse pacíficamente, sin armas, a dirigir convocaciones, reuniones, manifestaciones, marchas y piquetes (artículo 31).

Este último está aparentemente mejor definido que el anterior, sin embargo, está claro que la línea divisoria es bastante delgada, y que los términos «derecho» y «libertad» generalmente son considerados sinónimos. Otra dicotomía que tiene más significado legal que semántico es la división entre «humano» y «ciudadano», implementada en la Constitución. Aquí, la Constitución sigue el enfoque clásico según el cual los derechos humanos incluyen todos los derechos, excepto políticos. Los ciudadanos extranjeros, los apátridas, los refugiados y los desterrados no gozan de derechos políticos, pero están investidos de derechos personales, sociales, económicos y culturales (así como de derechos ecológicos, por si se los diferencia de los derechos económicos).

La aplicación de los derechos sociales, económicos y culturales a las categorías anteriormente mencionadas puede diferir en los detalles de procedimiento en comparación a la aplicación de tales derechos a los ciudadanos. Diversos artículos de la Constitución que estipulan derechos y libertades se acumulan en el Capítulo II, «Derechos y Libertades de los Humanos y Ciudadanos». En este Capítulo no se dispone más; si bien existen secciones, se encuentra la misma

LA JUDICATURA

EN EL SISTEMA

CONSTITUCIONAL

RUSO

JUDICIARY ON

RUSSIAN CONSTI-

TUTIONAL SYSTEM 
secuencia de los artículos establecidos para los derechos y libertades de conformidad con «las tres generaciones tradicionales de derechos humanos», y al menos las dos primeras generaciones claramente se suceden: los derechos personales y políticos (artículo 20-artículo 30), y los derechos sociales, económicos y culturales (artículo 34-44). El resto de artículos del Capítulo provee de las garantías formales de los derechos y libertades, tales como el principio de ne bis in idem (ítem 1, artículo 50), y hace hincapié en deberes específicos, como por ejemplo, el deber de los ciudadanos de proteger el país (ítem 1, artículo 59).

\section{III.1. Derechos personales}

Así como sugiere la teoría constitucional común, los derechos personales son considerados inalienables y naturales. Ellos pertenecen a la persona desde el momento de su nacimiento (aunque aún continúa el argumento que reconoce a los derechos humanos desde la etapa del feto) y no dependen de la ciudadanía.

El derecho personal fundamental es el derecho a la vida. Según el ítem 1, artículo 20 de la Constitución, todos tienen el derecho a la vida. El término «todos» abarca cada categoría constitucional de la persona, lo cual incluye a los ciudadanos y no ciudadanos. El derecho a la vida es considerado el derecho básico que sirve de condición necesaria para cada otro derecho humano.

La pena de muerte sigue siendo el asunto más controvertido en el presente. La Constitución no rechaza la pena de muerte, aunque formalmente limita su aplicación declarando que «la pena de muerte, hasta el momento de su abolición, puede ser establecida por una ley federal como una pena excepcional para los delitos más graves contra la vida, siempre que el acusado tenga el derecho a ser escuchado por un jurado» (ítem 2, artículo 20).

De hecho, la Federación Rusa es parte de la Convención Europea de Derechos Humanos (ECHR), la cual fue ratificada en 1998. El protocolo 6 de la ECHR, referido a la restricción de la pena de muerte, fue firmado en 1997, pero aún no ha sido ratificado. La moratoria en la pena de muerte fue introducida en la Federación Rusa poco tiempo después, hasta que los jurados fueran formados en todas las entidades que integran el país, y hasta que no hubiera ambigüedad respecto de si la pena de muerte puede ser ejecutada después de que todos los jurados fueran formados el 1 de enero de 2010.

Este asunto fue esclarecido por la Resolución de la Corte Constitucional de la Federación Rusa el 19 de noviembre de 2009 con número1344-O-R, donde la Corte declaró que el moratorio estable a largo plazo garantiza que los derechos humanos no ejecutados fueran formados, y que no es 
posible ejecutar la pena de muerte, aun cuando el veredicto fue hecho por un jurado respetuoso de las reglas formales.

Por lo tanto, y pese a la disponibilidad del procedimiento formal y la ambigüedad derivada de la no ratificación del mencionado Protocolo 6 , la pena de muerte no es considerada constitucional y no puede ser aplicada.

Además del derecho fundamental a la vida, la Constitución garantiza otros derechos personales y libertades inmanentes a los países democráticos: el derecho a la dignidad (ítem 1, artículo 21), el derecho a la seguridad —el cual incluye, entre otras cosas, la prohibición de la tortura, la violencia y otros tratos crueles o degradantes - (ítem 2, artículo 21), el derecho a la libertad e inviolabilidad personal (artículo 22), el derecho a la inviolabilidad de la vida personal, al secreto personal y familiar, la protección al honor y a la buena reputación (ítem 1, artículo 23), el derecho al secreto de la correspondencia, de las conversaciones telefónicas, postales, telegráficas y otros mensajes (ítem 2, artículo 23), el derecho de acceso a los documentos y materiales directamente relacionados con los derechos y las libertades (ítem 2, artículo 24), a la inviolabilidad del domicilio (artículo 25), el derecho a definir y afirmas la identidad étnica (ítem 1, artículo 26), el derecho a escoger el lenguaje de comunicación a la educación y creatividad (ítem 2, artículo 26), la libertad de movimiento y el derecho a la elección del lugar de la presencia y vida (ítem 1, artículo 27), el derecho a salir libremente y regresar a la Federación Rusa (ítem 2, artículo 28), la libertad de conciencia y culto (artículo 28), la libertad de pensamiento y expresión (ítem 1, artículo 29), la libertad a la información masiva (ítem 4, artículo 29).

\section{III.2. Derechos políticos}

Los derechos políticos son considerados como los derechos fundamentales del ciudadano. El límite a los derechos políticos se reserva a los ciudadanos extranjeros que tengan su domicilio dentro de un municipio. Esos ciudadanos extranjeros tienen derecho a votar y a ser elegido como autoridades municipales por los mismos motivos que los ciudadanos rusos, así como se contempla en un tratado internacional de la Federación Rusa ${ }^{18}$.

A menudo se interpreta que los derechos políticos consisten en dos tipos de derechos: (i) los derechos a participar en la formación y actividad del

18 Ver párr. 2, ítem 1, artículo 3 de la Ley Federal «Sobre los principios generales de las Autoridades Municipales en la Federación de Rusia» del 6 de octubre de 2003, № 131-FZ, artículo 12 «Sobre la condición jurídica de los extranjeros en la Federación Rusa” del 25 de julio de 2002, № 115-FZ y artículo 3 de la Ley Federal «Sobre las garantías de los derechos constitucionales de los ciudadanos de la Federación Rusa a elegir y ser elegidos en las Autoridades Municipales» del 26 de noviembre de 1996. De notarse que la Constitución formalmente separa al Estado y a los poderes municipales, los cuales sirven como fundamento de esta excepción.

LA JUDICATURA EN EL SISTEMA CONSTITUCIONAL RUSO

JUDICIARY ON

RUSSIAN CONSTITUTIONAL SYSTEM 
Estado y otras autoridades estatales a través de las diferentes formas de democracia representativa y directa, y (ii) los derechos a contribuir a la sociedad civil. El primer grupo de derechos incluye el derecho a votar y a ser elegido y el derecho a presentar peticiones. El segundo grupo generalmente representa una solicitud de derechos de las personas relacionadas con la información vinculada a la esfera de la política pública, tales como la libertad de expresión, la libertad de información masiva y la libertad de reunión.

La Constitución establece las garantías legales para cada uno de los grupos en los artículos 29-33. La esencia del primer grupo de derechos políticos está concentrada en el artículo 32 de la Constitución. Este artículo provee a los ciudadanos rusos el derecho a participar en la política pública, sea de manera directa o a través de representantes (ítem 1); a votar y ser elegidos como autoridades estatales o municipales, así como a participar en referéndum (ítem 2), a la igualdad de acceso de los ciudadanos al servicio del Estado (artículo 4), a formar parte de la administración de justicia (artículo 5). Las personas con discapacidad legal y aquellos que cumplen una pena de prisión en virtud de una sentencia judicial están privados del derecho a votar y a ser elegidos. $\mathrm{Al}$ respecto, el ítem 3, artículo 4 de la Ley Federal «Sobre las principales garantías de los ciudadanos de la Federación Rusa sobre los derechos electorales y sobre el derecho a participar en referéndum» del 12 de junio de 2002, № 67-FZ contiene una limitación adicional:

Los ciudadanos rusos que tengan ciudadanía de otro Estado o cualquier otro documento que les permita residir en otro país de manera permanente no pueden ser elegidos (enmienda del 25 de julio de 2006), pero conservan su derecho a votar. Tales ciudadanos solo pueden ser elegidos como autoridades municipales con las mismas limitaciones que se establecen para los ciudadanos extranjeros.

Hubo un intento de impugnar esta disposición en la Corte Constitucional de la Federación Rusa, pero la demanda fue luego desestimada por la Resolución del 4 de diciembre de 2007, № 797-S, con el argumento de que la disposición impugnada es clara y formalmente no está comprendida entre las disposiciones que puedan ser objeto de revisión.

Este enfoque es considerado discutible por algunos estudiosos, lo cual se refleja en el hecho de que existe una opinión disidente sobre la resolución mencionada. El artículo 30 de la Constitución garantiza el derecho de asociación y a la libertad de las asociaciones. Por el contrario, nadie puede ser obligado a ingresar a una asociación o a permanecer en ella. Este derecho es elaborado en una variedad de leyes federales, que incluyen el Código Civil de la Federación Rusa; la Ley Federal «Sobre las Asociaciones Públicas» del 19 de mayo de 1995, № 82-FZ 
y la Ley Federal «Sobre las organizaciones no comerciales» del 12 de enero de 1997, № 7-FZ. En el contexto de los derechos políticos, las asociaciones que constituyen partidos políticos son los más importantes. Estos se rigen por la Ley Federal «Sobre los partidos políticos» del 11 de julio de 2001, № 95-FZ.

El partido político es una asociación pública cuyo objetivo es dotar a los ciudadanos de la Federación Rusa de la posibilidad de participar en la vida política del país, mediante la formación y la expresión de su voluntad política, tomando así parte en la acción pública y política, en las elecciones y los referendos, así como en la representación de sus intereses ante las autoridades públicas.

Los objetivos estatutarios de los partidos políticos generalmente corresponden a los modelos elaborados por la ciencia política, e incluyen la formación de la opinión pública, la socialización política, la expresión de la opinión de la gente sobre los asuntos públicos y la nominación para las elecciones.

Un partido funciona bajo los principios de voluntariedad, de igualdad, de autonomía, de legalidad y de transparencia, y no puede violar ningún derecho constitucional. Está prohibido incorporar partidos extremistas y partidos basados en pertenencias profesionales, de raza, nacionalidad o religiosa. La última restricción fue debatida en la Corte Constitucional de la Federación Rusa (en la parte de las limitaciones respecto de la nacionalidad y religión), pero se resolvió en la decisión del 15 de diciembre de 2004, № 18-P que esta no contravenía la Constitución, cuando se refiere al principio del Estado laico y a lo referente a la experiencia de democracia limitada de los partidos políticos rusos. Los ciudadanos extranjeros y los no ciudadanos no pueden ser miembros de un partido político, así como tampoco los ciudadanos rusos considerados legalmente incapaces por la Corte.

Además del aspecto político de la libertad de pensamiento y expresión, y la consecuente libertad en los aspectos de información de masas, las instituciones de la sociedad civil requieren los derechos a reunirse pacíficamente (sin armas) y a llevar a cabo convocatorias, reuniones, manifestaciones, marchas y piquetes (artículo 31 de la Constitución).

Las definiciones y procedimientos son proporcionados por la Ley Federal del 9 de junio de 2004, № 54-FZ, «Sobre las convocatorias, reuniones, manifestaciones, marchas y piquetes». Los principios en los que se basan tales eventos públicos son los de legalidad y voluntariedad. Los eventos públicos están sujetos al requisito de notificación y, por regla general, deben llevarse a cabo en lugares específicos. La lista de tales lugares está determinada por una regulación de las autoridades regionales o municipales. Es posible conducir un evento en otro lugar, siempre que las 
autoridades estén previamente de acuerdo con ello. Un representante de la autoridad competente debe estar presente en el evento, tanto para controlar su legalidad como para apoyar al organizador. Un evento público debe ser interrumpido de manera forzada en caso de inminente amenaza a la salud, vida o propiedad cuando los participantes realicen actos ilegales (lo cual incluye irregularidades en el procedimiento), o cuando el organizador no haya notificado de manera previa a las autoridades, según el procedimiento establecido en la ley.

\section{III.3. Derechos sociales, económicos y culturales}

El moderno complejo de derechos sociales, económicos y culturales fue declarado por primera vez en 1948, a través de la Declaración Universal de los Derechos Humanos (artículos 22-27), y elaborado en 1966 por el Pacto Internacional de Derechos Económicos, Sociales y Culturales. Algunos de estos derechos también fueron desarrollados en los documentos de la Organización Internacional del Trabajo y en los tratados regionales, como por ejemplo la Carta Social Europea (1961, revisada en 1996), de la cual la Federación de Rusia es parte desde el 2000, aunque no ha sido ratificada aún.

Tal como lo establece el artículo 22 de la Declaración Universal de Derechos Humanos: «Toda persona, como miembro de la sociedad, tiene derecho a la seguridad social y a obtener, mediante el esfuerzo nacional y la cooperación internacional, habida cuenta de la organización y los recursos de cada Estado, la satisfacción de los derechos económicos, sociales y culturales, indispensables a su dignidad y al libre desarrollo de su personalidad». Por lo tanto, las peculiaridades específicas de este grupo de derechos humanos presuponen que estos están dirigidos al bienestar económico personal y a la adecuada calidad de vida, que implican programas de desarrollo social de un Estado, que sean interpretados en el sentido de una reclamación del ciudadano al Estado y que dependan en las condiciones económicas y recursos del Estado. En cierto modo, tales peculiaridades son reflejadas en la Constitución ${ }^{19}$.

El objetivo de los derechos sociales es proveer igualdad en la calidad de vida y accesibilidad a los beneficios sociales. La Constitución garantiza el acceso al seguro de trabajo, con la respectiva remuneración no discriminatoria, no inferior al mínimo legal, así como a la protección contra el desempleo (punto 3 del artículo 37); al derecho al descanso y tiempo libre, incluyendo las vacaciones anuales retribuidas (ítem 5, artículo 37); a la protección de la maternidad, niñez y familia (ítem 1, artículo 38); el apoyo social por razones de edad, enfermedad, discapacidad, pérdida del sostén de la familia, crianza de los hijos o en 
otros casos establecidos por la ley (Ítem 1, artículo 39); el derecho a la vivienda —que incluye la prohibición de privación de la vivienda de manera arbitraria - (artículo 40); la protección de la salud y la asistencia médica (artículo 41). A menudo estos derechos son interpretados en la teoría de los derechos constitucionales y humanos como derivación del derecho fundamental a la calidad de vida, declarada por el artículo 7 de la Constitución, la cual dibuja una conexión entre este derecho y la identificación de la Federación Rusa como un Estado social.

Los derechos económicos incluyen tres grupos principales: los relacionados con los negocios, con la propiedad y con el trabajo. Todos gozan del derecho a emplear sus capacidades y activos de manera libre, ya sea para la actividad empresarial o para cualquier otra actividad legítima, pero respetando la competencia leal (artículo 34). La propiedad privada y la sucesión están garantizadas y protegidas. Todos pueden disponer de sus propiedades de manera libre; una persona solo puede ser privada de su propiedad en virtud de una sentencia de un tribunal competente, y la asignación de los activos del Estado, de ser posible, debe prever que sea dado un reembolso de igual valor (artículo 35). Además, la Constitución explícitamente permite tener tierras en propiedad privada, con las limitaciones razonables relacionadas con las consideraciones ambientales y el uso justo (artículo 36). Finalmente, la Constitución declara la libertad de trabajo, prohíbe el trabajo obligatorio, y posibilita conflictos laborales específicos y huelgas legítimas (ítem 1, 2 y 4, artículo 37).

En adición, el artículo 42 de la Constitución establece que toda persona tiene derecho al medio ambiente favorable, a la correcta información sobre el estado del medio ambiente y al reembolso de los daños causados por una infracción ecológica. Existe una disputa sobre si considerar a este derecho como uno de carácter económico, o perteneciente a una categoría específica, la de los «derechos ecológicos».

Los derechos culturales aseguran la correcta socialización, el desarrollo intelectual personal y, en muchos aspectos, la autorrealización. Tal categoría de derechos incluye el derecho a la educación, el acceso a los valores culturales, a participar en las actividades culturales de la sociedad, a crear trabajos y otros derechos relevantes. En la Federación Rusa, cada uno tiene derecho a la educación, que garantiza la educación preescolar, la educación general y la educación secundaria especializada, y todos estos son accesibles gratuitamente en las instituciones estatales y municipales (ítems 1 y 2, artículo 43). Todos (incluyendo a los no ciudadanos) tienen derecho a recibir educación superior de forma gratuita por motivos de competencia en la institución estatal o municipal (punto 3 del artículo 43). Todos están garantizados con la libertad de cualquier forma de creatividad, incluyendo el arte, la ciencia y la tecnología; la libertad de enseñanza y la propiedad intelectual están protegidas por 
la ley (ítem 1, artículo 44). Toda persona tiene derecho a participar en actividades culturales y a tener acceso a los valores culturales (ítem 2, artículo 44).

\section{III.4. Los límites de los derechos humanos}

Según un viejo dicho constitucional, «Tu derecho a balancear los brazos termina justo donde la nariz del otro hombre empieza ${ }^{20}$. La Constitución establece que la lista de derechos humanos y libertades que ella misma dispone no debe ser interpretada exhaustivamente en comparación a otros derechos y libertades generalmente reconocidos (ítem 1, artículo 55), y que la ley que los suprima o menosprecie no se puede adoptar (ítem 2, artículo 55). Sin embargo, está permitido establecer límites razonables a los derechos humanos, generalmente siguiendo la lógica del procedimiento debido.

En particular, y de conformidad con el ítem 3, artículo 55, los derechos y libertades de los seres humanos y ciudadanos pueden verse limitados en la medida que sea ello necesario para proteger los fundamentos del orden constitucional, la moral pública, la salud, los derechos y los intereses legítimos de otras personas, la defensa del país y la seguridad del Estado.

Cualquier derecho y libertad garantizado por la Constitución puede ser dado como ejemplo. Por ejemplo, puede tomarse en consideración la libertad de los medios de comunicación. La Constitución de la Federación Rusa prevé la libertad de los medios de comunicación, y de acuerdo con el ítem 5 del artículo 29: «La libertad de los medios de comunicación está garantizada. La censura está prohibida».

A primera vista, esta disposición parece servir como una barrera sin ambigüedades para cualquier forma de limitación del contenido. Por otra parte, la Ley Federal del 27 de diciembre de 1991, № 2124-1, «Sobre los Medios Masivos» (en lo sucesivo «Ley de los Medios Masivos»), estipula la prohibición de censurar a los medios de comunicación, que puede darse en los casos de exigir a la junta editorial de un medio de comunicación que se ponga de acuerdo con funcionarios, autoridades estatales, organizaciones, fundaciones o asociaciones públicas sobre los mensajes y el contenido (con excepción de los casos en que un funcionario sea autor o la persona entrevistada), así como en el caso de prohibir difundir cualquier mensaje, contenido, o las partes de estos (párrafo 1 del artículo 3).

Adicionalmente, no está permitido crear ni proporcionar fondos para las fundaciones, organismos u oficinas que puedan realizar censuras 
(párrafo 2 del artículo 3). Por otro lado, hay razones obvias para interpretar de manera estricta las disposiciones mencionadas. Aparentemente, el jefe editor jefe de un medio de comunicación puede y debe tener el poder para filtrar el contenido, ya que es la persona que toma las últimas decisiones sobre el contenido y forma la política del medio de comunicación. Otro ejemplo es el derecho de un autor (aun cuando se trate de un funcionario público), a la integridad de la obra y a la protección de las distorsiones derivadas del artículo 1266 del Código Civil de la Federación de Rusia. Estas consideraciones, junto a otras igual de relevantes, fueron ratificadas por la Decisión № 16 del Pleno del Tribunal Supremo de la Federación de Rusia el 15 de junio de 2010 «Sobre la práctica de la aplicación de la Ley de los Medios de Comunicación por los Tribunales de la Federación de Rusia» (artículo 14).

En adición, la Ley de los Medios de Comunicación proporciona otra razón para la interpretación estrecha de la disposición sobre la censura establecida por la Constitución, la cual recibió el apoyo de la mencionada decisión también. El artículo 16.1 de la Ley de los Medios de Comunicación establece las bases para «cerrar» un medio de comunicación en caso de que este último abuse de su posición en el transcurso de las elecciones o referéndum. Por otra parte, la Ley Federal del 25 de julio de 2002, № 114-FZ, «Sobre la lucha contra las actividades extremistas», prohíbe usar los medios de comunicación para la difusión de materiales extremistas, y permite a los funcionarios públicos exigir la prohibición de difundir contenidos extremistas. En ambas situaciones, el caso debe ser escuchado en la corte para garantizar una decisión justa. La cuestión principal a determinar es si la prohibición a tal contenido en los medios masivos cae dentro de «censura» o no, considerando que este término no tiene definición legal explícita.

La cuestión principal es verificar si es que la prohibición de contenidos en medios de comunicación se clasifica como censura o no, ya que este término no tiene una definición legal explícita. Sin embargo, se puede considerar que la legislación rusa no considera como censura los actos que están dirigidos a la protección del interés público, estos están claramente delimitados por las leyes aplicables al caso concreto. Por otro lado, la decisión de la Corte Constitucional en estos casos debe ser buscada, aunque los ejemplos en la experiencia occidental no se alineen fácilmente a esta aproximación, en consonancia a los valores implícitos al sistema constitucional ${ }^{21}$.

21 Uno puede pensar en un ejemplo que se refiere al derecho constitucional de otro / libertad (es decir, el derecho a expresarse con libertad prevista por la Primera Enmienda de la Constitución de los Estados Unidos), pero es sustancialmente relevante para el tema en cuestión y se refleja en el caso: Nacional Socialist Party of America vs. Village of skokie, 432 U.S.43 (1977), también conocido como el "asunto Skokie". 
En cualquier caso, consideraciones similares deben ser relevantes para otros derechos y libertades garantizados por la Constitución. Mientras no sean abolidas o minimizadas, las leyes federales proveen limitaciones, generalmente razonables, dictadas por las consideraciones de otros derechos, libertades o interés público legítimo, o establecen procedimientos a través de los cuales los derechos y libertades correspondientes deben ser actualizados.

\section{TRIBUNAL CONSTITUCIONAL Y REVISIÓN JUDICIAL}

\section{IV.1. Panorama general}

En aplicación del artículo 125 de la Constitución de la Federación Rusa, la Corte Constitucional está investida de la autoridad para revisar la constitucionalidad de los actos normativos. Esta hace uso de esta autoridad judicial autónoma e independiente de los demás órganos judiciales (tribunales de jurisdicción ordinaria y tribunales de arbitraje estatal). Sin embargo, ello no significa que otras cortes estén prohibidas de evaluar los instrumentos normativos sobre la base de las disposiciones constitucionales. En concordancia con el artículo 15(1) de la Constitución, este tiene efecto jurídico supremo y es directamente aplicable.

A pesar de que había cierto número de recomendaciones de la Corte Suprema de Rusia a los tribunales menores de las jurisdicciones generales sobre cómo aplicar la Constitución en caso de que actos normativos entren en conflicto con sus disposiciones ${ }^{22}$, en la práctica raramente los jueces ejercen esta autoridad. Por otra parte, el efecto del juez de constatar que una disposición legislativa contradice las normas constitucionales se limitaría solo a ese caso.

Los procesos judiciales constitucionales buscan así rectificar cierto problema sistémico derivado de la inconstitucionalidad de un acto normativo. Los procesos son regulados por la Ley Federal Constitucional sobre la Corte Constitucional de la Federación Rusa de 1994 (en adelante, la ley de 1994) ${ }^{23}$. En concordancia con la ley, la función principal de la Corte Constitucional es proteger los fundamentos del sistema constitucional y los derechos humanos y de los ciudadanos, así como las libertades, y asegurar la supremacía y el efecto directo de la Constitución en la totalidad del territorio de la Federación Rusa ${ }^{24}$.

22 Ver, por ejemplo, Orden del Pleno de la Corte Suprema de la Federación Rusa del 31 de octubre de 1995 , № 8.

23 Ley Federal Constitucional sobre el Tribunal Constitucional de la Federación Rusa del 21 de julio de 1994 № 1-FKZ.

24 Ibíd., artículo 3. 
A tal efecto, la Corte Constitucional está facultada para llevar a cabo dos tipos principales de control de constitucionalidad: el abstracto y concreto. El control abstracto está destinado a determinar la constitucionalidad de actos normativos, con independencia de su aplicación por los tribunales en otros procedimientos. El derecho a iniciar este tipo de control está limitado al presidente, a cualquiera de las salas del Consejo de la Federación, a una quinta parte de los miembros de cualquiera de estas, al gobierno, a la Corte Suprema, a la Corte Suprema de Arbitraje del Estado, o a los órganos legislativos y ejecutivos de las entidades constitutivas de la Federación de Rusia. La lista exhaustiva de las materias para el control de constitucionalidad incluye:

a) Leyes federales, actos normativos emitidos por el presidente de la Federación de Rusia, el Consejo de la Federación, la Duma del Estado y el gobierno de la Federación Rusa.

b) Las constituciones de las Repúblicas, las cédulas, así como las leyes y otras disposiciones normativas emitidas por las entidades constitutivas de la Federación Rusa sobre materias pertenecientes a la jurisdicción de la Federación y a la jurisdicción conjunta de las autoridades federales y las autoridades de las entidades constitutivas de la Federación.

c) Los acuerdos entre la Federación y las entidades constitutivas de la Federación, y los acuerdos entre las entidades constitutivas de la Federación.

d) Los tratados internacionales de la Federación de Rusia pendientes de entrada en vigor ${ }^{25}$.

Sin embargo, una mayoría abrumadora de casos que la Corte Constitucional ha escuchado hasta ahora cae bajo el procedimiento del control judicial concreto, donde la Corte examina el cumplimiento de los actos normativos (en su mayor parte las leyes federales) con la Constitución Política, aplicado por otros tribunales en casos individuales.

A través del control concreto, la Corte Constitucional decide sobre las denuncias de violaciones de los derechos constitucionales y las libertades de las personas, y por lo tanto, examina la constitucionalidad de una ley que se ha aplicado a un caso concreto ${ }^{26}$. Por lo tanto, la mayoría de quejas constitucionales son, en efecto, tipos específicos de recursos contra las decisiones judiciales dictadas sobre la base de la ley impugnada.

25 lbíd., artículo 3.

26 El artículo 96 de la ley de 1994 estipula que el derecho a presentar una denuncia individual o colectiva sobre la violación de los derechos constitucionales y las libertades pertenece a los ciudadanos, cuyos derechos y libertades han sido violados por la ley que ha sido aplicada a un caso específico, y a las asociaciones de ciudadanos, así como a otros órganos y personas, de conformidad con la ley federal. El requisito de que la ley impugnada haya sido aplicada por una corte no es absoluto: basta con que el caso del demandante demuestre una estrecha relación entre su situación y la disposición legislativa en cuestión. Ver juicio del 27 de junio de 2012, № 15-P.

LA JUDICATURA

EN EL SISTEMA

CONSTITUCIONAL

RUSO

JUDICIARY ON

RUSSIAN CONSTI-

TUTIONAL SYSTEM 
Recientemente, la ley de 1994 fue enmendada y una nueva forma de control de constitucionalidad fue introducida ${ }^{27}$. La Corte Constitucional está ahora facultada — a iniciativa de otras cortes — para realizar el control de constitucionalidad de una ley «que debe aplicarse» por una corte respectiva en un caso específico. Esta enmienda fue el resultado de una iniciativa legislativa de la Corte Constitucional ${ }^{28}$, la cual fue sometida a la crítica de profesionales y académicos. Las facultades de control de la Corte Constitucional también incluyen el examen de conflictos de competencia entre los organismos gubernamentales federales, organismos gubernamentales federales y los órganos de las entidades constitutivas de la Federación Rusa, y entre los órganos estatales supremos de las entidades constitutivas de la Federación de Rusia $^{29}$; la interpretación de la Constitución ${ }^{30}$, o la emisión de una opinión sobre la observancia del procedimiento establecido para cobrar al presidente de una alta traición o por la comisión de otro delito grave ${ }^{31}$.

En concordancia con el artículo 79 de la ley de 1994, una decisión de la Corte Constitucional es definitiva y no está sujeta a apelación. Las decisiones de la Corte Constitucional son directamente aplicables y no requieren la afirmación posterior de otro órgano ni funcionario. Una decisión judicial de la Corte Constitucional que declara inconstitucional determinado acto no puede ser anulada por una nueva adopción del mismo acto. Los actos o sus disposiciones individuales encontradas inconstitucionales, se vuelven nulas y sin efecto. Del mismo modo, si un tratado internacional de la Federación de Rusia hasta su entrada en vigor se encuentra en conflicto con la Constitución, no entrará en vigor y tampoco será aplicado. Las decisiones de las cortes y otros órganos basadas en los actos o disposiciones individuales de los mismos que hayan sido declarados inconstitucionales por sentencia de la Corte Constitucional no deben ser ejecutadas y deberán ser revisadas por los cortes que las han expedido. Sin embargo, tal control no sigue automáticamente la conclusión de la Corte Constitucional, ya que requiere una moción especial del demandante, la cual debe ser presentada ante el tribunal que emitió la decisión basada en el acto inconstitucional ${ }^{12}$.

El tiempo límite para tal moción es de tres meses. No está claro si la declaración de inconstitucionalidad de una ley autoriza a otras personas, aparte del demandante en el procedimiento de control de constitucionalidad, a solicitar la revisión de sus casos basados en la aplicación de la misma ley. La Corte Constitucional por sí misma ha

27 Artículo 3.3.1 de la Ley Federal Constitucional del 3 de noviembre de 2010, № 7-FKZ.

28 Según el párr. 6 del artículo 3 de la ley de 1994, la Corte Constitucional tiene el derecho a «tomar la iniciativa legislativa sobre asuntos relativos a su jurisdicción».

29 lbíd., artículo 3.2.

30 lbíd.

31 lbíd.

32 La llamada revisión basada en una circunstancia recién descubierta. 
demostrado diferentes enfoques de esta cuestión ${ }^{33}$. Sin embargo, hay ejemplos de casos que han sido revisados por las cortes de jurisdicción general, independientemente de si los demandantes eran parte en el procedimiento ante la Corte Constitucional.

Cuando un acto normativo es encontrado inconstitucional en todo o parte por una decisión de la Corte Constitucional, o cuando existe la necesidad de llenar una laguna en la regulación legal surgida de una decisión de la Corte Constitucional, el órgano del Estado que ha adoptado tal acto normativo tiene la obligación de adoptar un nuevo instrumento normativo que debe, en particular, proveer una abrogación de la ley normativa declarada inconstitucional o introducir las modificaciones necesarias a un acto normativo encontrado parcialmente inconstitucional. Hasta que un nuevo acto normativo sea promulgado, la Constitución —o en su lugar la interpretación llevada a cabo por una decisión de la Corte Constitucional- regirá las relaciones en cuestión de manera directa, a menos que la Corte decida lo contrario ${ }^{34}$. La implementación de las decisiones de la Corte Constitucional ha sido problemática: según las estadísticas, solo el 30\% de sus decisiones ha sido implementado de manera apropiada por el legislador ${ }^{35}$.

Una reciente enmienda a la ley que rige la labor de la Corte Constitucional ha ampliado sus poderes de elaboración de leyes, y por lo tanto, se ha convertido en un tema controversial ${ }^{36}$. En concordancia con la nueva regla, el hallazgo (literalmente «posición») de la Corte Constitucional en la constitucionalidad del significado del acto normativo, derivado de su aplicación en la práctica por otras cortes, debe ser tomado en consideración de manera obligatoria por los órganos del Estado desde el momento en que entra el vigor la de la sentencia respectiva de la Corte Constitucional.

Esta nueva provisión inmediatamente se ha convertido en materia de un recurso de inconstitucionalidad. En sentencia, la Corte sostuvo que esta novedad es de conformidad con la Constitución y explicó su «significado constitucional» ${ }^{37}$.

33 Cf. Las decisiones de la Corte Constitucional del 14 de enero de $1999, N^{\circ} 4-O$ y del 12 de mayo de 2006 № $135-\mathrm{O}$.

34 Por ejemplo, en un reciente caso sobre la constitucionalidad de la tutela plenaria sobre los adultos con discapacidad mental, la Corte, mediante su juicio del 27 de junio de 2012, invalidó el marco actual del Código Civil el 1 de enero de 2013 y exigió al legislador aprobar las modificaciones necesarias antes de esa fecha (ver juicio № 15-P). La enmienda requerida fue adoptada el 30 de diciembre de 2012, no obstante, su entrada en vigor fue suspendida por dos años, con lo cual se ha hecho caso omiso a la conclusión de la Corte Constitucional.

35 Ver la opinión del juez supremo G. Zhilin sobre la sentencia del Tribunal Constitucional del 27 de junio de 2012 № 15-P.

36 Ver Ley federal constitucional del 3 de noviembre de 2010, № 4-FKZ.

37 Ver sentencias del 8 de noviembre de 2012 № $25-\mathrm{P}$ en el caso sobre la constitucionalidad de las disposiciones del artículo 79 de la Ley Constitucional Federal «Sobre el Tribunal Constitucional de la Federación de Rusia» (The JSC Pipeline products Transnefteproduct).

LA JUDICATURA

EN EL SISTEMA CONSTITUCIONAL RUSO

JUDICIARY ON RUSSIAN CONSTITUTIONAL SYSTEM 
La Corte argumentó que la noción de «posición» de la Corte Constitucional debe ser entendida como que la Corte puede establecer el significado constitucional de un acto normativo determinado, el cual requiere otros organismos gubernamentales, incluidos los tribunales, para que se abstengan de aplicarlos en cualquier otro sentido. Por otra parte, la declaración de inconstitucionalidad puede afectar no solo a la propia normativa, sino también a cualquier interpretación inconstitucional de aquella.

La «inconstitucionalidad» es, por lo tanto, una interpretación que no es de conformidad con el significado constitucional recientemente establecido. En otras palabras, si la Corte Constitucional explica el significado de ciertos actos normativos, incluso cuando otros altos tribunales de la Federación, como la Corte Suprema y la Corte Suprema de Arbitraje, hayan establecido diferentes interpretaciones, todas las cortes deben seguir la «nueva» interpretación establecida por la Corte Constitucional en todos los procedimientos, incluso los instituidos antes de que dicha sentencia fuera aprobada. Tal interpretación de la Corte Constitucional se vuelve «genuina» y único entendimiento legalmente válido del acto normativo.

El mencionado significado constitucional del nuevo artículo, sin duda, ha ampliado los límites del poder de la Corte Constitucional, en comparación con su lectura literal. El concepto de «posición de la Corte Constitucional» elaborado en la práctica de la Corte y recientemente introducido en la legislación da lugar a nuevos $-\mathrm{y}$ revive viejosdebates sobre los límites del control de constitucionalidad llevado a cabo por la Corte y el rol de la Corte en el sistema de los órganos del Estado.

\section{IV.2. Oportunidades y desafíos}

En la práctica, la posición y la competencia de la Corte Constitucional son temas complicados, debatidos igualmente por académicos y profesionales. Muchos académicos han argumentado que de facto, los poderes de la Corte han ido más allá del marco de las disposiciones legislativas que rigen su labor. Esta era una consecuencia inevitable de la ampliación de las competencias de la Corte en el ámbito del control judicial concreto que siguió a la reducción de otras categorías de casos.

El análisis estadístico de la labor de la Corte durante los últimos años demuestra que el control judicial abstracto, el cual se espera sea la actividad central de la Corte Constitucional, es más bien un rudimento. La Corte aún no ha resuelto los conflictos de competencia entre los órganos estatales u organismos gubernamentales de las entidades constitutivas de la Federación. Solo una vez tuvo la Corte la oportunidad de llevar a cabo el control de constitucionalidad de 
un tratado internacional pendiente de entrada en vigor ${ }^{38}$. El último juicio de la Corte con respecto a la interpretación de la Constitución fue en 2000; hoy en día las peticiones son casi inexistentes. Más de 18000 quejas y peticiones se presentan ante la Corte Constitucional cada año, más del 90\% son denuncias individuales o colectivas sobre la violación de los derechos constitucionales y las libertades. El análisis temático de los casos ante la Corte Constitucional demuestra que la mayoría de las quejas trata de diversos aspectos de los derechos sociales y el derecho a la propiedad ${ }^{39}$.

La mayoría de casos que alegan violaciones a los derechos civiles y políticos se refieren a las garantías de un juicio justo en el contexto de un proceso penal, por lo tanto, la jurisprudencia de la Corte es la más elaborada en estas esferas. En el ámbito de los derechos civiles, una de las zonas progresistas de la jurisprudencia de la Corte es la salud mental: como una consecuencia de varias importantes sentencias, reformas a gran escala se han iniciado y muchas disposiciones discriminatorias respecto de la situación jurídica de las personas con discapacidad mental se han modificado.

Solo un un puñado de los recursos individuales presentados ante la Corte Constitucional son admitidos para el proceso de control. La mayoría de casos son rechazados sin siquiera examinar sus méritos. Sin embargo, en muchas ocasiones la Corte rechaza un caso por inadmisible, a veces a favor del solicitante.

Así, en un caso relativo al traslado institucional de las personas con discapacidad mental, la Corte desestimó la denuncia en la que el solicitante alegaba que fue colocado arbitrariamente en el hogar de cuidado social, en base a que la ley no exigía un control judicial para la colocación de una persona privada de capacidad jurídica ${ }^{40}$. Sin embargo, la Corte sostuvo que la ley impugnada debe interpretarse como que de hecho exige una orden judicial para tal colocación. Por otra parte, la Corte señaló la ausencia de procedimiento para esa revisión y requirió al legislador adoptarlo.

El cambio que se ha evidenciado en la categoría de los casos ante el Tribunal y la gradual modificación de sus poderes han dado lugar a la discusión sobre si la Corte excede los límites de su autoridad ${ }^{41}$ y si es que la lista tradicional de fuentes del derecho del ordenamiento jurídico ruso

38 Ver juicio de la Corte Constitucional del 9 de julio de 2012 № 17-P con respecto al protocolo sobre la adhesión al Acuerdo de Marrakech por el que se establece la Organización Mundial del Comercio. 39 Para las estadísticas oficiales de la Corte, ver www.ksrf.ru.

LA JUDICATURA

EN EL SISTEMA CONSTITUCIONAL RUSO

JUDICIARY ON

RUSSIAN CONSTITUTIONAL SYSTEM 
debe ser enmendada para incluir precedentes judiciales, y en particular las «posiciones legales» de la Corte Constitucional.

\section{IV.3. El exceso de poderes}

Se argumenta que desde el establecimiento de la Corte Constitucional en 1991, esta ha excedido regularmente su autoridad, debido a que la Corte ha interpretado predominantemente disposiciones de las leyes federales y no las de la Constitución. La Corte ha sido criticada por interpretar la Constitución sin tomar en consideración el actual sistema de regulación legal, y con ello, la introducción de nuevos fenómenos jurídicos. Además, la Corte de facto ha revisado las decisiones de otras cortes, actuando así como un tribunal de instancia superior ${ }^{42}$.

La razón por la que la Corte actúa ultra vires se ve en las vagas disposiciones de la ley de 1994, la cual rige su labor ${ }^{43}$. En la mencionada ley no se indica ningún criterio definido para determinar la constitucionalidad de una ley en cuestión, con excepción de las alegaciones de los demandantes. En otras palabras, la Corte Constitucional tiene discreción máxima y absoluta para decidir si las alegaciones de violación a los derechos humanos pueden o no ser remediada por medio de un recurso de inconstitucionalidad; es decir, si la demanda supera la prueba de admisibilidad ${ }^{44}$. Algunos estudiosos han sido llamados para el establecimiento de las condiciones de admisibilidad de fondo en la ley, que en nuestra opinión no es realista.

\section{IV.4. Función legislativa de facto de la Corte}

Una de las cuestiones más debatidas sobre el exceso de facultades de la Corte Constitucional es la autoridad de facto de elaborar normas. El problema de la Corte Constitucional en la elaboración de normas y las disputas en torno a ella se ha abordado con mayor detalle anteriormente (véase «frenos y contrapesos»). Sin embargo, entender la función de revisión judicial de la Corte exige una mirada más cercana a la fuerza jurídica de sus sentencias.

Los partidarios de la postura de que la Corte es un exclusivo cuerpo judicial de «aplicación de de la ley» enfatizan que, si una provisión es declarada inconstitucional, esta es derogada no por decisión de la Corte Constitucional, sino por la aplicación directa de los artículos pertinentes

42 Kurbatov, A. «Kompetenciya Konstitucionnogo Suda Rossiyskoy Federacii» (La competencia de la Corte Constitucional de la Federación Rusa). Zakon, 2004, 6. 43 lbíd.

44 En concordancia con el procedimiento de la ley de 1994, la decisión de inadmisibilidad puede tomar dos formas. Una decisión inicial es hecha por el Registro de de la Corte; si el solicitante no está de acuerdo, podrá pedir a la Corte que se pronuncie sobre esta cuestión. En este caso, el Tribunal podrá rechazar el caso por inadmisible o podrá decidir sobre sus méritos, ya sea en la cámara o en la audiencia pública. 
de la Constitución, lo que ha permitido a la Corte Constitucional evaluar la constitucionalidad de la disposición legislativa en cuestión.

Esta «vista conservadora» procede de la idea de que la jurisprudencia de la Corte no puede ser fuente de derecho en los países del sistema de derecho continental. En consecuencia, la Corte Constitucional nunca hace la ley ${ }^{45}$.

De conformidad con los oponentes del enfoque mencionado, el hecho de que la Constitución haya autorizado al Parlamento para legislar no significa que el legislador real o la fuente de la legislación sea la propia Constitución. Asimismo, afirman que hay una estricta división entre legislar y aplicar la ley, y que esto último tiene más bien un valor político.

LA JUDICATURA EN EL SISTEMA CONSTITUCIONAL RUSO

JUDICIARY ON RUSSIAN CONSTITUTIONAL SYSTEM

Tal división es relativa en algunos casos, ya que cada vez que la Corte establece una nueva norma jurídica, aplica esas reglas que limitan su poder legislativo ${ }^{46}$. Bajo esta «visión liberal» —como posiciones jurídicas de la Corte Constitucional-, las decisiones de la Corte pueden ser consideradas como una fuente de derecho, no solo en los países del Common Law. Al mismo tiempo, se argumenta que las decisiones de la Corte Constitucional son como precedentes en su naturaleza y que las posiciones jurídicas expresadas en ellas son ratio decidendi de la decisión ${ }^{47}$.

A menudo se admite a la Corte como legislador negativo cuando declara inconstitucionales algunas disposiciones legales. Esta declaración de inconstitucionalidad puede llevar a una interpretación restrictiva de una norma legal o a una pérdida de su eficacia jurídica. El caso de pena de muerte es emblemático en este sentido. A raíz de la decisión del Estado ruso de Duma de no ratificar el Protocolo № 6 al Convenio Europeo sobre la abolición de la pena de muerte, en 1999 la Corte estableció una moratoria sobre el castigo corporal hasta que los juicios con jurado se hubiesen establecido en todas las entidades constitutivas de la Federación de Rusia ${ }^{48}$.

Esto iba a suceder en 2010, y por lo tanto, en 2009, y a petición de la Corte Suprema de la Federación de Rusia, la Corte Constitucional emitió una aclaración a su sentencia de 1999, estableciendo que como resultado de la moratoria de larga duración sobre la pena de muerte «se han formado garantías estables para que los derechos humanos no se sometan a la pena de muerte y se ha desarrollado el régimen jurídico

45 NERSESYANTS, V. «U rossiyskih sudov net pravotvorcheskih polnomochiy» (Las cortes rusas no tienen poder para legislar). En Sudebnaya praktika kak istochnik prava (Práctica de la Corte como fuente de derecho). Moscú: Yurist, 2000, p. 112.

46 VerESHCHAGIN, A. «Yavlyaetsya li Konstitucionnyi Sud negativnym zakonodatelem?» (¿Es la Corte Constitucional un «legislador negativo»?) Zakon, $2010 \mathrm{~N}^{\circ}$ 1 1-8.

47 KOROTEYEV, K. «Pravovye pozicii Konstitucionnogo Suda Rossiyskoy Federacii: element procedury ili istochnik prava? " (Legal positions of the Constitucional Court of the Russian Federation: the element of the procedure or the source of law?) Zakon, 2009, pp. 61-68.

48 Sentencia de la Corte Constitucional del 2 de febrero de 1999, № 3-P. 
constitucional, lo que significa, en vista de las tendencias internacionales y las obligaciones legales de la Federación de Rusia, que ha tomado lugar un proceso irreversible hacia la abolición de la pena de muerte como una medida excepcional de castigo» ${ }^{49}$. La Corte, por lo tanto, llegó a la conclusión de que la aplicación de la resolución de 1999 «no abre la oportunidad de aplicar la pena de muerte, incluso en el marco de una convicción basada en el veredicto del jurado $»^{50}$.

Aun cuando una disposición legal es declarada constitucional, la Corte en muchas ocasiones impone la interpretación que - basada en la Constitución - pretende evitar cualquier otra aplicación que en la práctica pueda convertir la disposición legal es inconstitucional ${ }^{51}$. Por lo tanto, ya no es realista negar la autoridad de la Corte Constitucional para establecer nuevas reglas referidas a la doctrina de separación de poderes o al ordenamiento jurídico continental de Rusia.

Así sea solo la parte dispositiva de las decisiones de la Corte, o también su razonamiento judicial (en la terminología propia de la Corte «posiciones jurídicas»), que este constituya una fuente de derecho es una cuestión igualmente problemática.

El término «posición jurídica» puede ser encontrado, tanto en la anterior Ley sobre la Corte Constitucional de 1991 como en la actual Ley sobre la Corte Constitucional de 1994, en el contexto de la independencia de los jueces «de la influencia política e ideológica». En otras palabras, las decisiones de la Corte deben reflejar las opiniones jurídicas de los jueces - sus puntos de vista jurídicos y conclusiones-, pero no sus posiciones políticas. En este sentido, «la posición jurídica» se opone a la tendencia política de la Corte.

Según las enmiendas de 2010 a la ley de 1994, las «posiciones jurídicas» de la Corte Constitucional han dado lugar a diferentes significados, y por lo tanto, se han convertido en un tipo específico de normas jurídicas. No queda enteramente claro si una posición jurídica de la Corte es igual a su decisión. En los escritos académicos, así como en las propias decisiones de la Corte, el término «posición jurídica» ha sido utilizado para referirse tanto a la motivación de la Corte como a su parte dispositiva. Por lo tanto, a diferencia de la decisión de la Corte Constitucional — la cual es definitiva y no puede ser revisada-, una posición jurídica puede ser cambiada por la Corte en vista de los desarrollos modernos ${ }^{52}$.

49 Decisión de la Corte Constitucional del 19 de noviembre de 2009, № 1344-O-P.

50 lbíd.

51 Por ejemplo, en el caso relativo a una prohibición general de obtención de permisos de residencia para extranjeros con VIH, la Corte estableció que las disposiciones impugnadas para que sean compatibles con la Constitución.

52 Véase, por ejemplo, el cambio ya mencionado sobre el razonamiento de la Corte en relación con la abolición de la pena de muerte. Asimismo, en su sentencia de 2012, la Corte se refirió a «los niveles actuales de los derechos humanos» como la razón principal para declarar inconstitucional el sistema de tutela plenaria sobre los adultos (véase la sentencia del 27 de junio de 2012 № 15-P). 
Es más previsible que la Corte Constitucional considere que la fuerza jurídica de sus posiciones jurídicas sea la misma que la de sus decisiones, y que con ello formule la interpretación constitucional de las leyes y recomendaciones al legislador respecto de la adopción de nuevas normas o la modificación de las existentes.

Un ejemplo reciente es la sentencia relativa a las multas administrativas por la violación de las normas antimonopolio. La Corte sostuvo que, si bien existe un rango mínimo establecido en la ley, ello no excluye el derecho de las autoridades de imponer una situación debajo del rango mínimo. En consecuencia, la Corte sostuvo que hasta que la nueva ley no sea adoptada en la línea de esta sentencia, el Servicio Federal Antimonopolio puede reducir la multa sobre la base de las disposiciones de la Constitución y las «posiciones jurídicas de la Corte expresadas en la presente sentencia» ${ }^{53}$.

Esta posición de la Corte Constitucional demuestra su intención de ampliar sus competencias con el fin de informar al legislador sobre la necesidad de adoptar nuevas normas o modificar las ya existentes. Por otra parte, las referencias a las «posiciones jurídicas de la Corte Constitucional» ahora se pueden encontrar no solo en el razonamiento de sus decisiones, sino en su parte dispositiva ${ }^{54}$.

\section{EL DERECHO INTERNACIONAL DE DERECHOS HUMANOS Y LA JURISPRUDENCIA DE LA CORTE CONSTITUCIONAL DE LA FEDERACIÓN RUSA}

La interrelación entre la jurisprudencia de los órganos internacionales de derechos humanos y la Corte Constitucional de Rusia ha ofrecido a los eruditos y políticos rusos la oportunidad de revisar los enfoques de la soberanía del Estado y cuestionar los límites del escrutinio jurídico internacional de las obligaciones de Rusia, en virtud de tratados de derechos humanos.

Rusia forma parte de un gran número de instrumentos internacionales de derechos humanos, en particular del Convenio Europeo para la Protección de los Derechos Humanos y las Libertades Fundamentales de 1950 (en lo sucesivo, el Convenio Europeo de Derechos Humanos), de los Pactos Internacionales de 1966 (de Derechos Civiles y Políticos y de Derechos Económicos, Sociales y Culturales), los cuales se han convertido en parte del ordenamiento jurídico de la Federación de Rusia $^{55}$. Por otra parte, si un tratado internacional de la Federación de 
Rusia estipula otras reglas distintas de las previstas en la ley, las normas del tratado internacional prevalecerán ${ }^{56}$.

La Corte Constitucional aplica rutinariamente las decisiones del Tribunal Europeo de Derechos Humanos (y las de algunos otros órganos convencionales), analizando el alcance de las normas de derechos humanos en la Constitución. Además, con ello ha hecho hincapié en que no solo las disposiciones de la Convención Europea de Derechos Humanos son obligatorias para la Federación de Rusia, sino también la interpretación de estas disposiciones por el Tribunal Europeo de Derechos Humanos. Por tanto, deben ser tomados en cuenta por los órganos legislativos y los órganos de toma de decisiones en la elaboración o aplicación de las normas pertinentes ${ }^{57}$.

Hasta hace poco, La Corte Constitucional ha implementado ciertos estándares internacionales de derechos humanos en su jurisprudencia (en su mayoría de la Corte Europea de Derechos Humanos) ${ }^{58}$. Sin embargo, en varias ocasiones recientes las conclusiones de la Corte Constitucional han entrado en conflicto con las posiciones de los organismos internacionales de derechos humanos.

Esto puede ilustrarse en el caso de Konstantin Markin contra Rusia, en el que el Tribunal Europeo de Derechos Humanos no solo estableció una violación de la Convención Europea sino que rechazó explícitamente la investigación anterior de la Corte Constitucional sobre el mismo asunto $^{59}$. Esta sentencia de la Corte Europea ha provocado un acalorado debate sobre el papel de sus decisiones en el ordenamiento jurídico de un determinado Estado, y fue seguida por una serie de declaraciones críticas y cargadas de emociones del presidente de la Corte Constitucional, el señor Valery Zorkin.

Él señaló, en particular, que las decisiones de la Corte Europea no tienen en cuenta adecuadamente las «particularidades nacionales de cada país» ni «los aspectos específicos del desarrollo de cada país». Las autoridades locales están en mejor posición para entender las necesidades antes que

56 lbíd.

57 Por ejemplo, la sentencia de la Corte Constitucional de 02.05.2007 № 2-P.

58 Para un caso emblemático, véase la sentencia del 27 de febrero de 2009 № 4-P. En este caso, y sobre la base de las conclusiones de la Corte Europea y su sentencia Shtukaturov contra Rusia de 2008, la Corte Constitucional derogó diversas disposiciones legales relacionadas con los ensayos de incapacidad y el compromiso civil de las personas con discapacidad mental. Véase: BARTENEV, D. y MARCHENKO, «Implementation of Shtukaturov v. Rusia: Challenges and Strategies». Interights Bulletin 16, 2 (2010), pp. 63-66.

59 La Corte Europea sostuvo que a Markin, un militar ruso divorciado con un hijo recién nacido, se le negó injustamente su solicitud de licencia de padre por tres años, lapso también otorgado al personal militar femenino. La Corte sostuvo que la legislación militar rusa era discriminatoria por razón de sexo y pidió a Rusia modificar sus leyes. Véase: Konstantin Markin vs. Rusia [GC], demanda № 30078/06, sentencia de 22 de marzo de 2012. 
cualquier juez internacional, ya que ellos entienden «el código cultural, moral y religioso de Rusia» ${ }^{60}$.

También criticó al Tribunal Europeo por hacer una recomendación para enmendar la legislación rusa, considerando que ello constituye una violación de la soberanía nacional de un Estado. Zorkin enfatizó que es la Constitución la que hace que todos los acuerdos internacionales sean vinculantes para Rusia; si alguna de las disposiciones de un tratado internacional entra contradicción con la Constitución, esta disposición no se aplica.

Por lo tanto, concluyó que la Constitución establece los límites para el cumplimiento de las decisiones de la Corte Europea. Al mismo tiempo, sugirió que la Corte Constitucional «pueda convertirse en un lugar para el seguimiento y control de la ejecución de las decisiones de la Corte Europea de Derechos Humanos» ${ }^{61}$.

En vista de la tendencia a ampliar las facultades de la Corte Constitucional, sus futuras decisiones probablemente abordarán el tema del conflicto entre las posiciones de la Corte Constitucional y las de los organismos internacionales de derechos humanos. 